\title{
Convenience Analysis of Citizen Using Garden Green Space Basing on Road Network's Accessibility
}

\section{-A Case Study of Tai'an Central City}

\author{
Lin Ma1,2, Hongtao Wang1,2*, Bing Liu ${ }^{1,2}$ \\ ${ }^{1}$ Shandong Provincial Research Center of Demonstration Engineering Technology for Urban and Rural Landscape, Tai'an, China \\ ${ }^{2}$ College of Forestry, Shandong Agricultural University, Tai'an, China \\ Email: ^hongtao@sdau.edu.cn
}

How to cite this paper: Ma, L., Wang, $\mathrm{H}$. T., \& Liu, B. (2019). Convenience Analysis of Citizen Using Garden Green Space Basing on Road Network's Accessibility. Current Urban Studies, 7, 311-320. https://doi.org/10.4236/cus.2019.73015

Received: June 24, 2019

Accepted: August 31, 2019

Published: September 3, 2019

Copyright $\odot 2019$ by author(s) and Scientific Research Publishing Inc. This work is licensed under the Creative Commons Attribution International License (CC BY 4.0).

http://creativecommons.org/licenses/by/4.0/

\begin{abstract}
Green space accessibility can be used to measure the potential of green space to provide services to residents. Taking urban community as the basic unit, using GIS software and combining with the distribution of road network and population, convenience of every community to the nearest garden green space is analyzed with the aspect of time. Results show that $69 \%$ community can reach the nearest park green space within 5 minutes no matter which kind of transportation is used and the convenience of most communities are well. However, some community residents' convenience of arriving at the nearest park green space is bad (more than 10 minutes). These communities of which population accounted for 3.6\% are Jinxing Community and Lingzhi Community of Caiyuan Street Office and Yingchun Community and Nanhu Community of Daimiao Street Office.
\end{abstract}

\section{Keywords}

Road Network, Accessibility, City Resident, Garden Green Space, Convenience

\section{Introduction}

As an important part of the urban green space system, the area, quantity, spatial layout, planning and design of urban green space are directly related to the quality of the citizen's living environment and the daily recreational activities.

Accessibility which is an effective index to measure traffic network has been widely used in land planning (Geurs, 2004), urban planning (Wei \& Yang, 2016; Zhong et al., 2016), tourism planning (Jin et al., 2010; Pan \& Cong, 2012) and other fields. Green space accessibility is the relative or absolute difficulty of 
overcoming the resistance from any point in space to the green space and can be expressed by distance, time, cost and so on (Frank, 1999). The index can be used to measure the potential of green space to provide services to residents and has profound impact on the frequency of people such as elderly, children and disabled using the green space and other public service facilities (Alexis et al., 2008; Kyushik \& Jeong, 2007; Wong \& Jusuf, 2008).

Yu Kongjian et al. (1999) applied accessibility to the planning and evaluation of urban green space system earlier in China. Using spatial resistance model, accessibility distribution of green space system of Zhongshan city was got. According to the principle of GIS modeling, the calculation methods include buffer analysis method (Li et al., 2016), the minimum approach distance analysis method (Yin et al., 2008), the attraction index method (Zhou \& Guo, 2004; Hu et al., 2005), and the cost resistance analysis method (Ma \& Cao, 2006) and so on. These methods reflect the spatial accessibility of green space from different angles. Some scholars such as Yin Haiwei (2008), Li \& Liang (2009), Ma \& Lu (2011), Zhao et al. (2015) have applied the evaluation of accessibility to the research of green space system in various regions. However, these studies pay more attention to garden green space and pay less attention to the residents-whether they can arrive at the nearest garden green space conveniently. Based on spatial analysis function of GIS software, taking community as the basic unit and combining with road network distribution, the research studies convenience of community residents reaching the nearest garden green space from the point of time distance to represent travel convenience of each area residents and provide a new way for study of regional green space layout.

\section{Research Methods}

\subsection{Overview of the Study Area}

Tai'an City which Mount Tai is located in locates in central Shandong Province of China and its area is $6598 \mathrm{~km}^{2}$. Tai' an City is surrounded by mountains and lakes which ecological environment is excellent. The city's green coverage rate is $44.7 \%$ and the per capita garden green space area is $19.9 \mathrm{~m}^{2}$ in 2016 .

The scope of this study is the central district of Tai'an City, north to Mount Tai, west to the Great Wall Road, South to the Panhe Street, east to Shanggao Street, including Caiyuan Street Office, Daimiao Street Office and Taiqian Street Office. The total area is $36.4 \mathrm{~km}^{2}$.

\subsection{Data Sources}

The data sources used is the 1:10,000 map of land use type of Tai' an city of 2012 . Green space data is provided by Tai'an Municipal Bureau of Parks and the community population data is from the sixth national census of 2010 .

\subsection{Evaluating Indicator}

The evaluation index of the accessibility of the park green space from any point 
in the research area is:

$$
A_{i}=\min \left(M_{j} T_{i j}\right)
$$

$i$ refers to any point in the research area. $T_{i j}$ refers to the time of point $i$ arriving at Park $j$ through the shortest route of the traffic network. $M_{j}$ refers to the weight of park $i$. Regardless of landscape attraction and other factors, traffic accessibility is considered only and the weight is $1 . A_{i}$ refers to accessibility of point $i$ within the area.

\subsection{Procedure of Accessibility Calculation}

1) Preparation of source files

Based on the ARC/INFO software, the garden green space information was extracted from the land use map (Figure 1).

2) Preparation of travel cost documents (road network documents)

Based on the ARC/INFO software, the road network information is extracted from the land use map (Figure 2).

Tai'an central city is divided into several grids and every grid is $30 \mathrm{~m} * 30 \mathrm{~m}$. Relative to $36.4 \mathrm{~km}^{2}$ of the central city area, each grid area is small enough which can be regarded as internal homogeneous units and the accessibility is the same.

Time is the standard for measuring accessibility, so space distance is transferred into time distance through the speed. That is the time of the city residents moving a grid $(30 \mathrm{~m})$. There are three trip modes in the study: walking, non motor vehicles and motor vehicles. The road network is divided into three levels: main roads, secondary roads and branches. Different speeds and travel cost are set to different level of roads. The travel costs of taking different transportation are shown in Table 1.

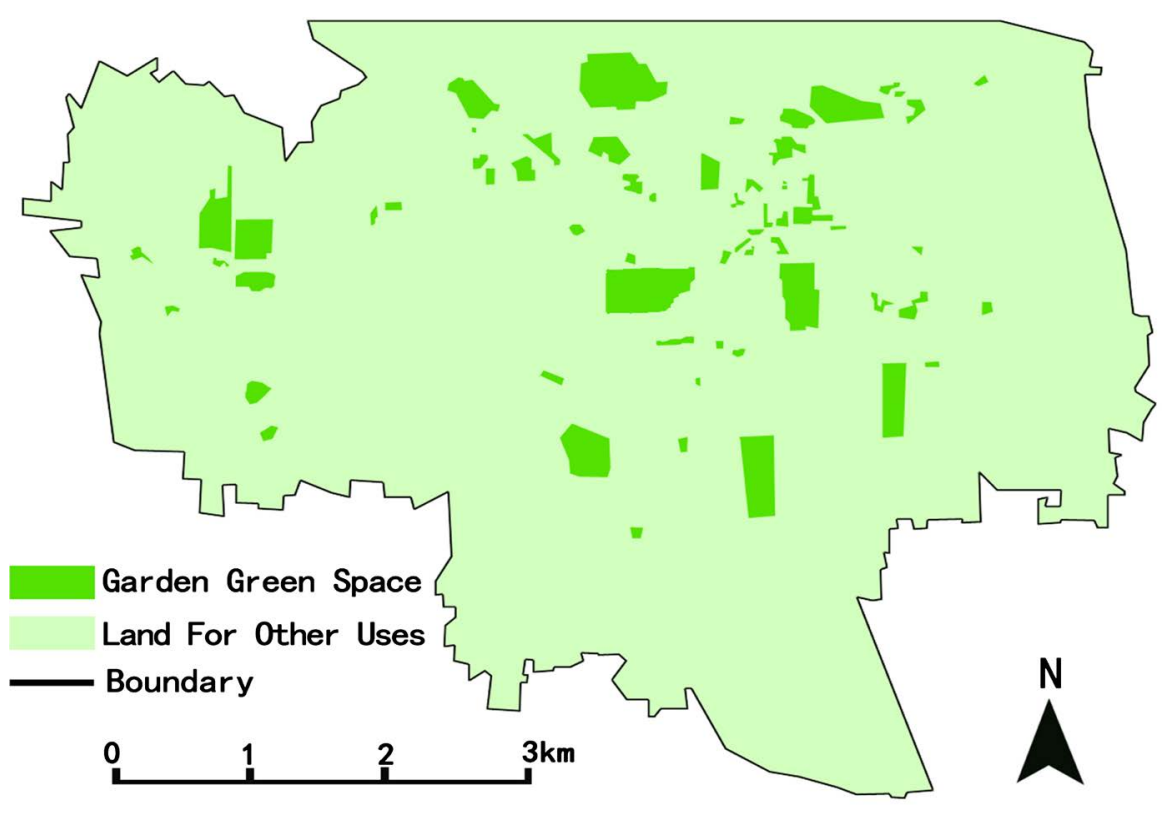

Figure 1. Distribution of garden green space. 


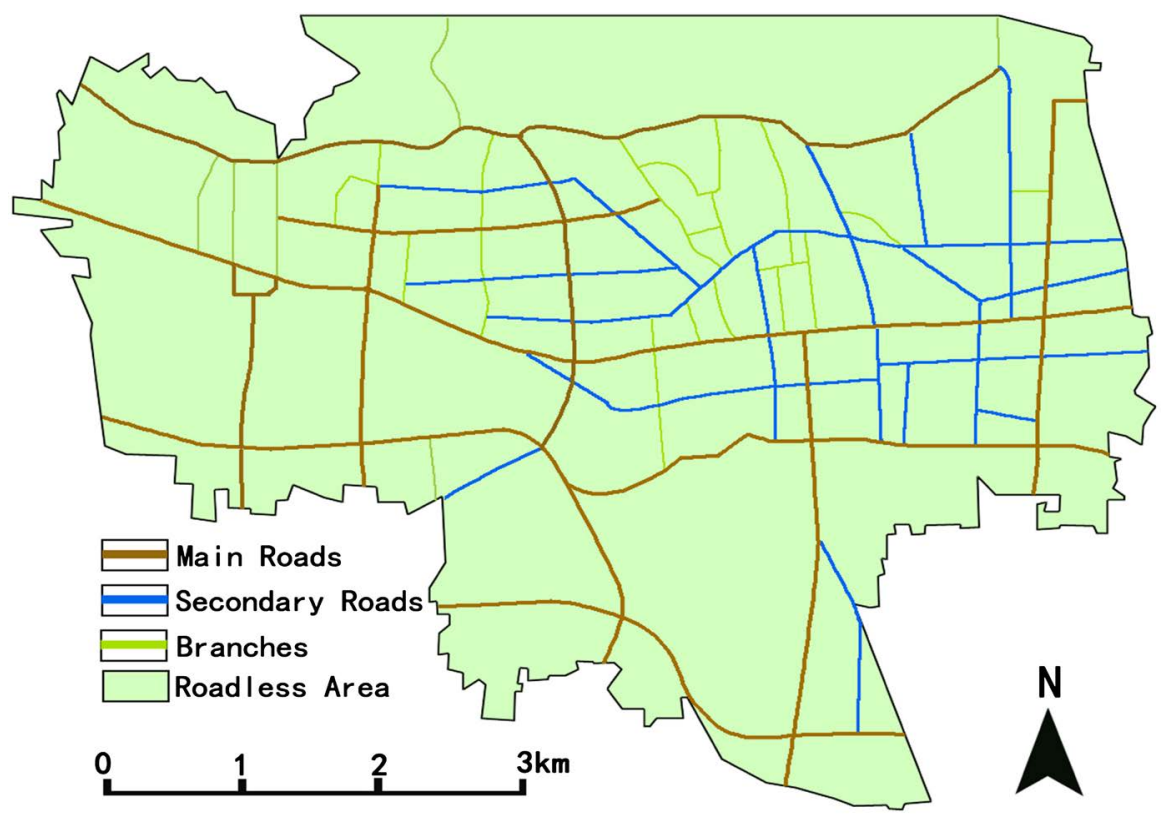

Figure 2. Distribution of road network.

Table 1. Values of travel cost.

\begin{tabular}{ccccccc}
\hline & \multirow{2}{*}{ Walking } & \multirow{2}{*}{$\begin{array}{c}\text { Non-motor } \\
\text { vehicle }\end{array}$} & \multicolumn{3}{c}{ Motor vehicle } \\
\cline { 4 - 6 } & & & main roads & secondary roads & branches \\
\hline Average speed $(\mathrm{km} / \mathrm{h})$ & 5 & 15 & 60 & 45 & 30 \\
Values of travel cost (s/grid) & 21.6 & 7.2 & 1.8 & 2.4 & 3.6 \\
\hline
\end{tabular}

3) Preparation of community population data

Basing on the ARC/INFO software, according to the existing streets and community divisions, the central city is divided into 58 communities to calculate every community population (Figure 3 ).

4) Calculation of travel convenience of every community residents

ARCGIS software is used to calculate the time of each grid to the nearest garden green space and then accessibility of the entire study area is got.

The index of evaluating travel convenience of community residents is:

$$
R_{j}=\sum_{j=1}^{n_{j}} A_{i} / n_{j}
$$

$n_{j}$ refers to grids number within the scope of $j$ community, $A_{i}$ refers to accessibility of the $i$ grid and $R_{j}$ refers to residents travel convenience of the $j$ community. The index of accessibility of the average time within the community to reflect the whole community grid the level of accessibility, the shorter the time, the community to park more convenient; convenient to describe the extent of community residents daily use of green on the whole, the visual display of park green space accessibility distribution in the community on the level of space. 


\section{Results and Analysis}

The minimum value of each garden green space to any point of the study area through the traffic network are calculated of three kinds of traffic modes, namely the accessibility of the point to the garden green space. Distribution characteristics of garden green space accessibility are showed and analyzed on 5 minute period (Figure 4).

Figure 4 shows that no matter which kind of transportation is adopted, most parts of the study area can reach the nearest garden green space within 5 minutes

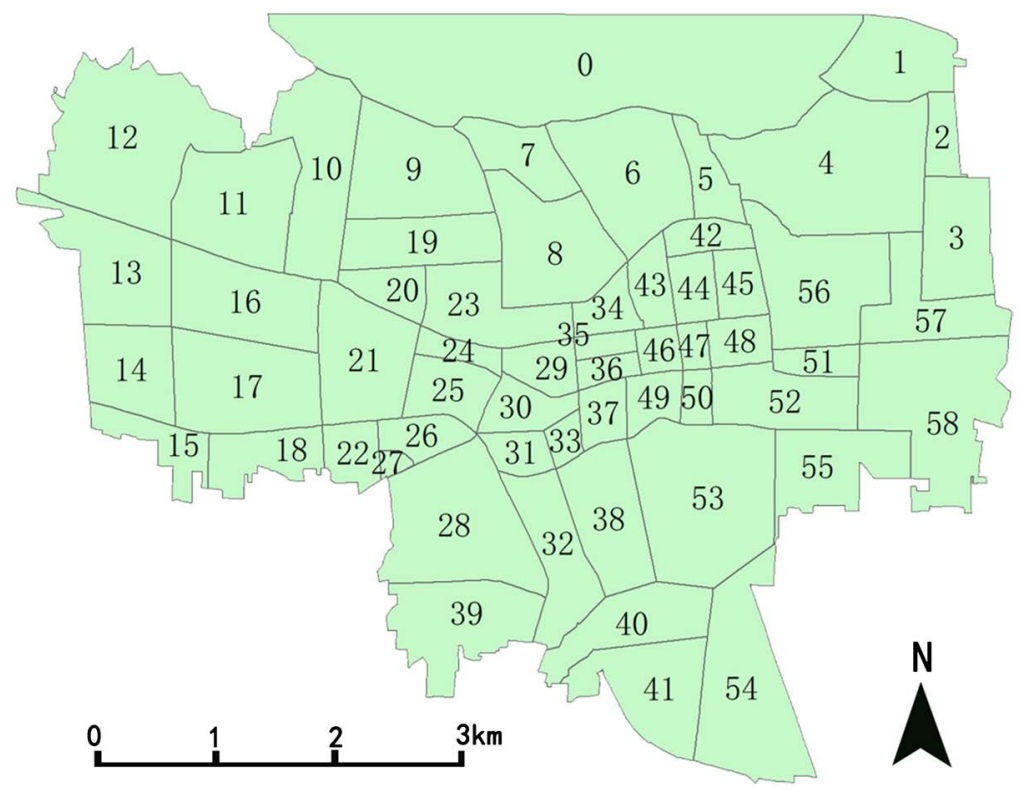

Figure 3. Distribution of communities.

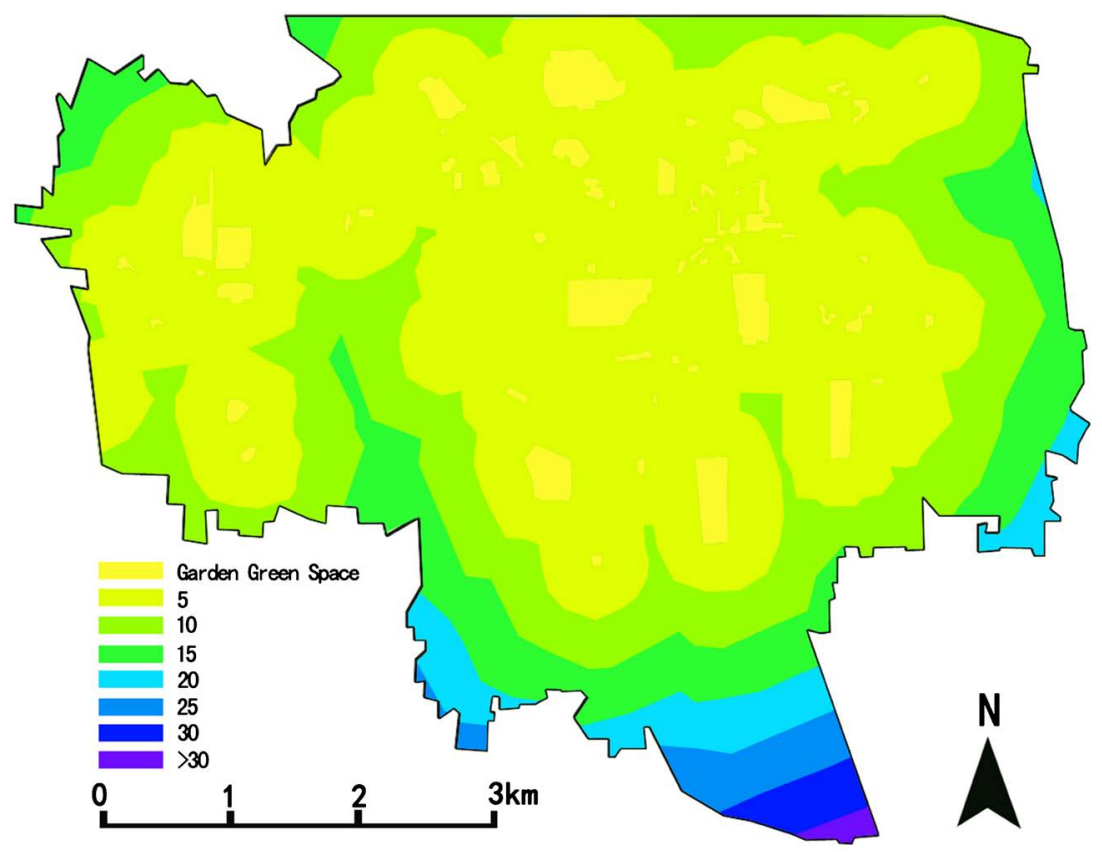

(a) 


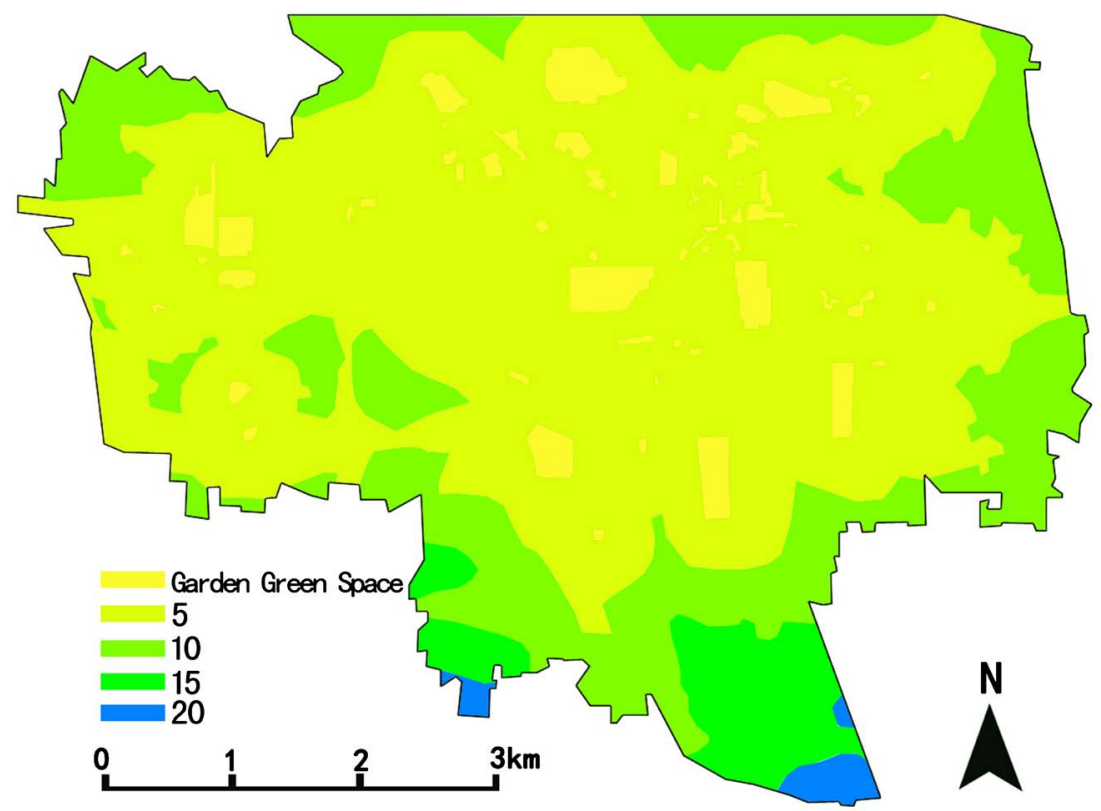

(b)

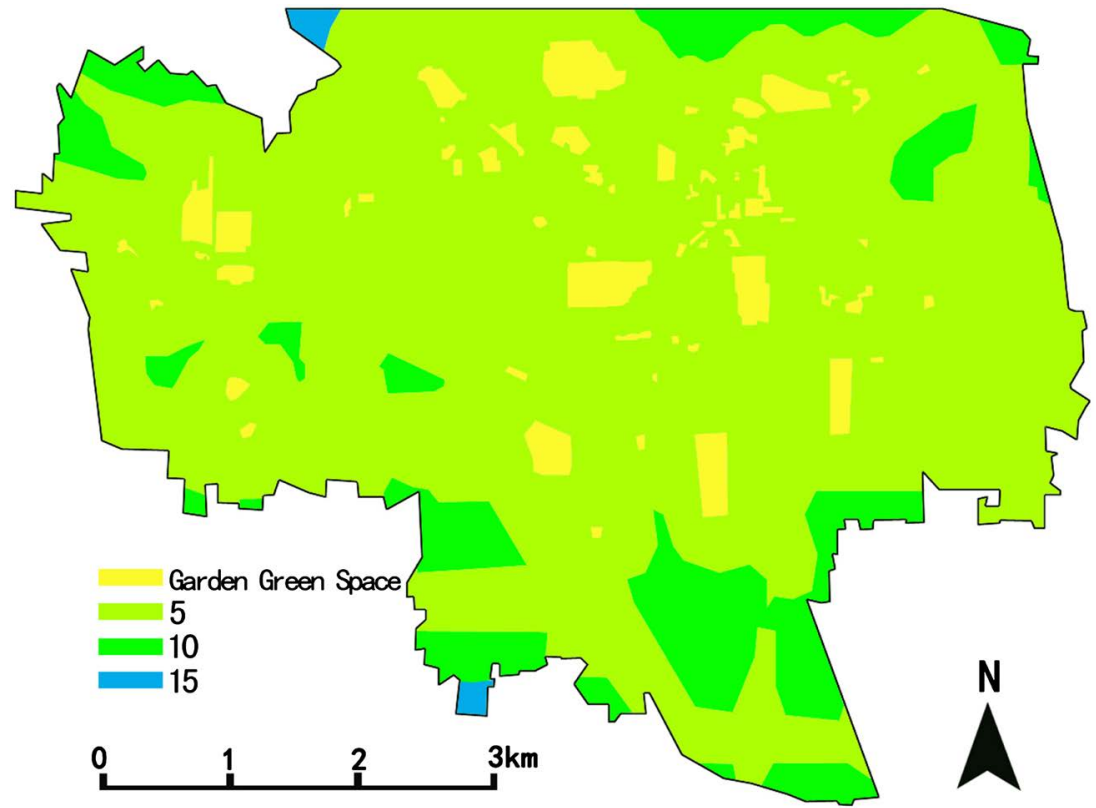

(c)

Figure 4. Distribution of garden green space accessibility by different transportation (unit: min). (a) Walking; (b) By non-motor vehicles; (c) By motor vehicles.

and the overall accessibility is well. The area accounted for $62.0 \%, 83.6 \%$ and 93.6\% within 5, 10 and 15 minutes by walking. The area accounted for $71.4 \%$ and $85.1 \%$ of non-motor vehicles and motor vehicles respectively.

Taking the community as the research object, the above results combing with the community distribution are computed using grids and the convenience of community residents arriving at the nearest garden green space is got. Communities are divided into several types (Figure 5) and related statistics are calculated 
according to the average reaching time by 5 minute intervals.

Results show that:

1) Residents accounted for $79.7 \%$ of 40 communities which are located in the center of the research zone can reach the nearest garden green space within 5 minutes on foot. Residents of 49 communities and 56 communities can reach the nearest garden green space respectively within 10 minutes and 15 minutes, Area of these communities accounted for $84 \%$ and $94.6 \%$ and population of these communities accounted for $92.6 \%$ and $97.7 \%$. In addition, residents of 2 communities (Guanzhuang and Nanhu) which population accounted for $2.3 \%$ reach the nearest garden green space more than 15 minutes.

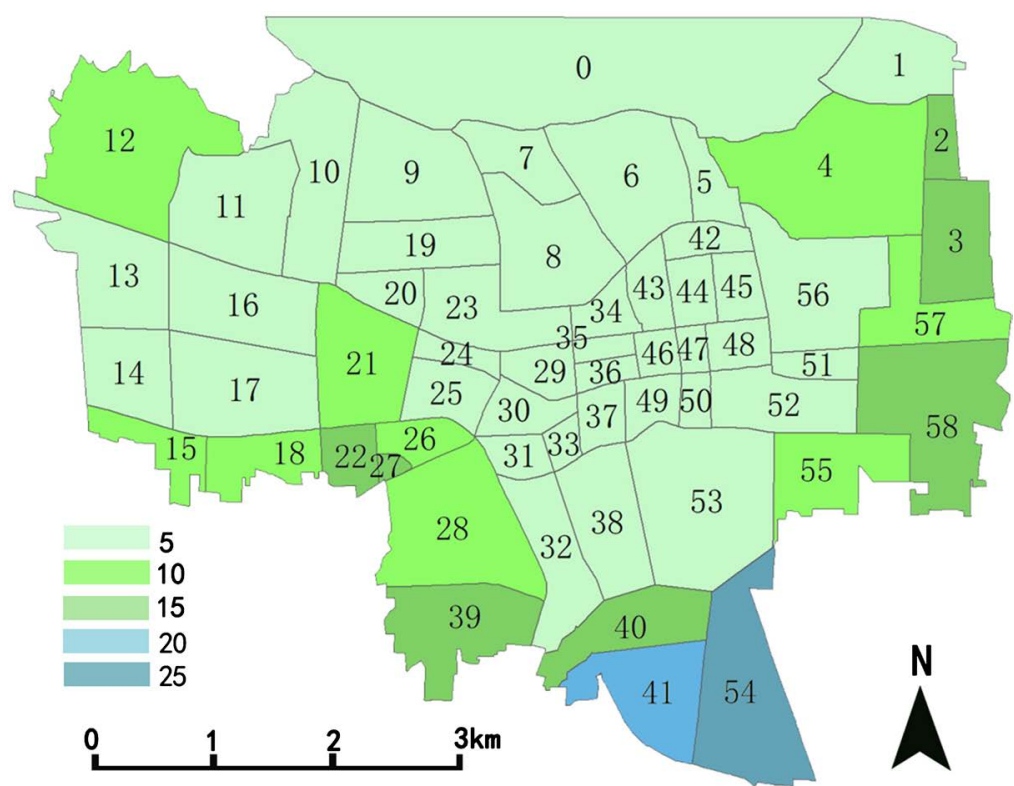

(a)

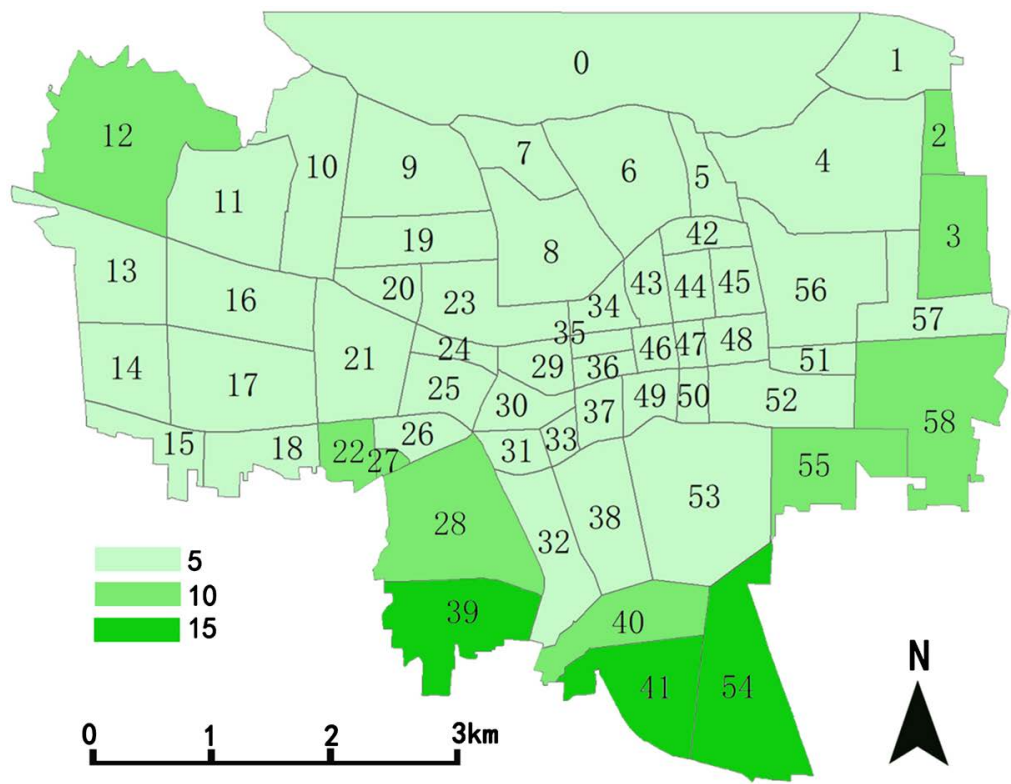

(b) 


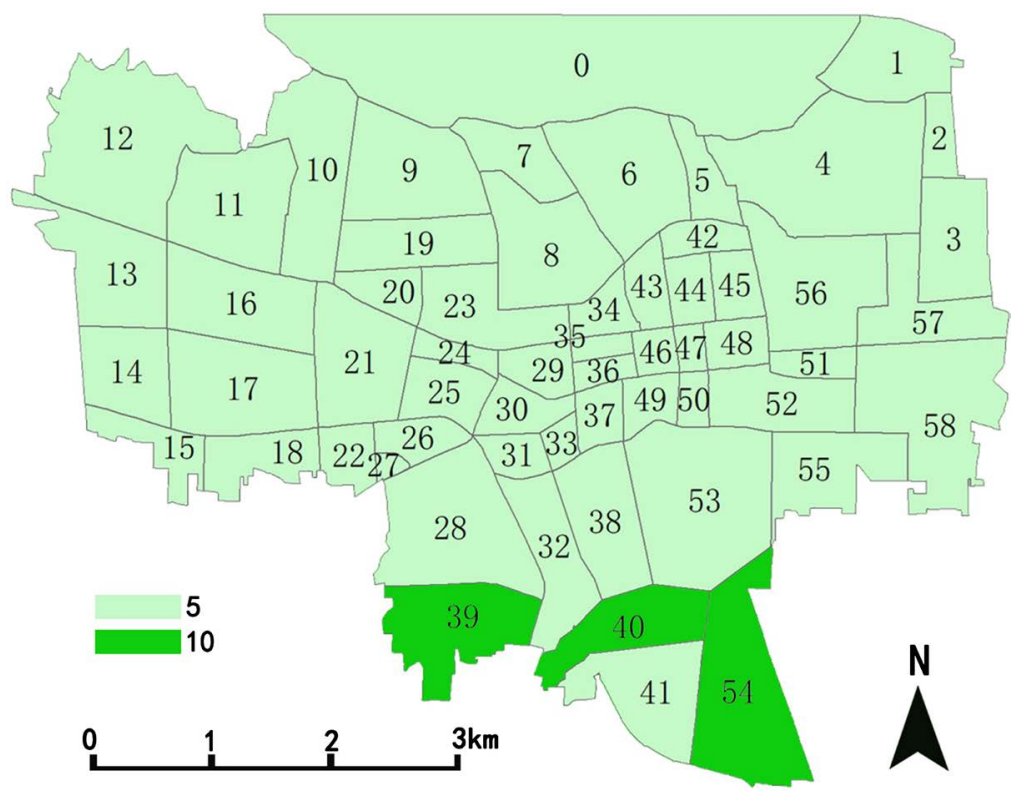

(c)

Figure 5. Convenience distribution of community residents arriving at the nearest garden green space (unit: min). (a) Walking; (b) By non motor vehicles; (c) By motor vehicles.

2) By non-motorized modes, residents accounted for $89.6 \%$ of 46 communities which area accounted for $74.2 \%$ can reach the nearest garden green space within 5 minutes. Residents of 55 communities can reach the nearest garden green space within 10 minutes and residents of all communities can reach the nearest garden green space within 15 minutes. Accessibility of such communities as Lingzhi (11 minutes), Guanzhuang (11 minutes) and Nanhu (13 minutes) are low which population accounted for $3.6 \%$.

3) By motorized modes, residents accounted for $96.4 \%$ of 55 communities which area accounted for $92.7 \%$ can reach the nearest garden green space within 5 minutes. Residents of all communities can reach the nearest garden green space within 10 minutes. Accessibility of such communities as Lingzhi (6 minutes), Guanzhuang (7 minutes) and Nanhu (6 minutes) are still low.

In summary, no matter which kind of transportation mode is adopted, residents accounted for $79 \%$ (communities accounted for $69 \%$ ) can reach the nearest garden green space within 5 minutes, so the convenience are well. No matter which kind of transportation mode is adopted, convenience of residents of some communities is bad (more than 10 minutes). These communities of which population accounted for $3.6 \%$ are Jinxing Community and Lingzhi Community of Caiyuan Street Office and Yingchun Community and Nanhu Community of Daimiao Street Office.

\section{Conclusion and Discussion}

Taking communities as the basic unit, based on the spatial analysis function of GIS software and combining with the road network distribution, convenience of 
community residents reaching the nearest garden green space is studied using the time which provides a new way for spatial structure study of city green space system. The research draws the following conclusions: the whole accessibility of garden green space of Tai'an central city is well and accounted for more than $70 \%$ community residents can reach the nearest garden green space conveniently (within 5 minutes). However, no matter which kind of transportation mode is adopted, convenience of residents of some communities (accounted for 3.6\%) which lie on the boundary of the central city is bad (more than 10 minutes).

Convenience of residents arriving at the garden green space is influenced by factors including distribution of the road network, the population and the garden green space and the landscape quality of the garden green space. In the paper, landscape attraction of the garden green space isn't considered which is an important direction for future research.

In the paper, garden green space data of 2012 and population distribution data of 2010 are analyzed. If more data can be got in the future, convenience characteristics can be studied dynamically and more completely which can play a positive impact on the scientific planning and management of the city.

\section{Conflicts of Interest}

The authors declare no conflicts of interest regarding the publication of this paper.

\section{References}

Alexis, C., Chris, B., \& Edmund, G. (2008). Using a GIS-Based Network Analysis to Determine Urban Green Space Accessibility for Different Ethnic and Religious Groups. Landscape and Urban Planning, 86, 103-114.

Frank, E. M. (1999). Integrating Accessibility. Landscape Architecture.

Geurs, K. (2004). Accessibility Evaluation of Land-Use and Transport Strategies Review and Research Directions. Journal of Transport Geography, 12, 127-140. https://doi.org/10.1016/j.jtrangeo.2003.10.005

Hu, Z. B., He, X. Y., Lu, Q. X. et al. (2005). Green Space Accessibility Research Based on GIS: Taking Shenyang as an Example. Journal of Shenyang Architectural and Civil Engineering Institute, 21, 671-675.

Jin, C., Lu, Y. Q., \& Fan, L. L. (2010). Research on Accessibility of Scenic Spots in the Yangtze River Delta Based on Land Traffic Network. Journal of Natural Resources, 25, 258-269.

Kyushik, O., \& Jeong, S. (2007). Assessing the Spatial Distribution of Urban Parks Using GIS. Landscape and Urban Planning, 82, 25-32. https://doi.org/10.1016/j.landurbplan.2007.01.014

Li, J. Y., Shi, T., Yan, H. W. et al. (2016.) Accessibility Based on Optimization of Green Space Pattern-A Case Study of Shenyang. Journal of Northwest Forestry University, 31, 285-290.

Li, X. M., \& Liang, C. F. (2009). Accessibility and Service of Shenyang's Urban Parks by Network Analysis. Acta Ecologica Sinica, 29, 1554-1562.

Ma, L. B., \& Cao, X. S. (2006). A GIS-Based Evaluation Method for Accessibility of Urban 
Public Green Landscape. Acta Scientiarum Naturalium Universitatis Sunyatseni, 45, 111-115.

Ma, L., \& Lu, Y. Q. (2011). Research on Landscape Accessibility of City Green Space Based on Traffic Network-Case Study of the Garden Green Space of the City Proper of Nanjing. Journal of Chinese Landscape Architecture, 7, 92-96.

Pan, J. H., \& Cong, Y. B. (2012). Spatial Accessibility of Scenic Spot at 4A Level and Above in China. Scientia Geographic Sinica, 32, 1321-1327.

Wei, D. K., \& Yang, Q. N. (2016). Walking Reachability of Urban Public Space: Nangang District, Harbin. Planner, 32, 93-97.

Wong, N. H., \& Jusuf, S. J. (2008). GIS-Based Greenery Evaluation on Campus Master Plan. Landscape and Urban Planning, 84, 166-182. https://doi.org/10.1016/j.landurbplan.2007.07.005

Yin, H. W. (2008). Urban Open Space-Pattern, Accessibility and Agreeable. Nanjing: Southeast University Press.

Yin, H. W., Kong, F. H., \& Zong, Y. G. (2008). Accessibility and Equity Assessment on Urban Green Space. Acta Ecologica Sinica, 28, 3375-3383.

Yu, K. J., Duan, T. W., \& Li, D. H. (1999). Landscape Accessibility as a Measurement of the Function of Urban Green System. City Planning Review, 23, 8-11+43.

Zhao, B., Li, L. L., \& Cao, L. (2015). GIS-Based Analysis of City Park Green Space Service Range and Layout Optimization-A Case Study in Huaqiao International Business City. Journal of Chinese Landscape Architecture, 31, 95-99.

Zhong, Y. X., Fu, Y., \& Feng, X. H. (2016). The Accessibility patterns and City Types Based on Passenger Rail Transport in China. Resources and Environment in the Yangtze Basin, 25, 1645-1653.

Zhou, T. G., \& Guo, D. Z. (2004). GIS-Based Researches on Urban Green Space on Landscape Gravity Field with Ningbo City as an Example. Acta Ecologica Sinica, 24, $1157-1163$. 